\title{
Comunicação interna e liderança aberta: os desafios de incorporar a geração $Y$ e as mídias sociais
}

Internal communication and open leadership: the challenges of incorporating generation $Y$ and social media

Comunicación interna y liderazgo abierto: los desafíos de incorporar a la generación $Y$ y a las redes sociales

- Jornalista, com mestrado e doutorado em Ciências da Comunicação pela Escola de Comunicações e Artes da Universidade de São Paulo (ECA-USP)

- Especialista em Comunicação Rural

- Professor do Programa de Pós-Graduação em Comunicação Social da Universidade Metodista de São Paulo (Umesp)

- Editor de oito sites temáticos em comunicação/jornalismo

- Líder do grupo de pesquisa "Comunicação empresarial no Brasil: uma leitura crítica (Criticom)", da Umesp

- Autor de vários livros e dezenas de capítulos em livros da área

- Diretor da Comtexto Comunicação e Pesquisa e da Mojoara Editorial

- E-mail:wilson@comtexto.com.br 
Resumo

A comunicação interna precisa se adaptar ao novo ethos organizacional, incorporando as características e as demandas de parcela importante dos seus públicos internos, constituída por representantes da chamada Geração Y. Ao mesmo tempo, deve estar empenhada em construir uma autêntica cultura de comunicação em rede. 0 artigo evidencia a necessidade de mudanças importantes no modelo de gestão e nas posturas dos gestores das organizações brasileiras, em particular nos processos, ações e estratégias de comunicação que caracterizam a comunicação interna. Propõe a introdução do sistema de liderança aberta para garantir o efetivo comprometimento dos funcionários, favorecer a construção de uma clima organizacional saudável e reter os verdadeiros talentos das organizações.

PALAVRAS-CHAVE: COMUNICAÇÃO INTERNA • COMUNICAÇÃO E GESTÃO • COMUNICAÇÃO E MÍDIAS SOCIAIS • GERAÇÃO Y.

\section{Abstract}

Internal communication needs to adapt to new organizational ethos, incorporating the characteristics and demands of a significant portion of their internal audiences, consisting of representatives of the so-called Generation Y. At the same time, it must be committed to building a true culture of network communication. The article highlights the need for major changes in the management model and the attitudes of managers in Brazilian organizations, in particular the communication processes, actions and strategies that characterize internal communication. The article proposes the introduction of open leadership to ensure effective involvement of employees, promote the building of a healthy organizational atmosphere and retain organizations' true talents.

KEYWORDS: INTERNAL COMMUNICATION • COMMUNICATION AND MANAGEMENT • COMMUNICATION AND SOCIAL MEDIA • GENERATION Y.

\section{Resumen}

La comunicación interna debe adaptarse a la nueva filosofía organizacional, incorporando las características y exigencias de parte importante de su público interno, compuesto por representantes de la llamada Generación Y. Al mismo tiempo, debe estar comprometida con la construcción de una verdadera cultura de la comunicación en red. El artículo pone de relieve la necesidad de cambios importantes en el modelo de gestión y las actitudes de los directivos de las organizaciones brasileñas, en particular, los procesos, acciones y estrategias de comunicación que caracterizan la comunicación interna. Propone la introducción de liderazgo abierto para asegurar la participación efectiva de los trabajadores, promover la construcción de un clima organizacional saludable y retener a los verdaderos talentos de las organizaciones. 


\section{ANO 10 • NÚMERO $19 \cdot 2$ 2oㅡ 2013 • ORGANICOM \\ COMUNICAÇÃO INTERNA E LIDERANÇA ABERTA:

m fato incontestável é que o mundo do trabalho tem sofrido, especialmente nas duas últimas décadas, mudanças estruturais, tendo em vista a necessária adaptação a fatores políticos, econômicos e socioculturais que o têm impactado de forma dramática.

A globalização dos mercados impõe novas circunstâncias às organizações, as quais se veem - abruptamente em alguns casos - diante de desafios importantes que chegam a ameaçar a sua própria sobrevivência. Essa situação pode ser avaliada pelo número crescente de fusões e aquisições e pela presença de muitas empresas em mercados com características muito distintas daqueles em que estavam acostumadas a operar. Fora de seu "hábitat" político, econômico e social de origem, as organizações enfrentam embates provocados por diferenças culturais, linguísticas, trabalhistas ou sindicais, envolvendose em crises e conflitos de repercussão internacional, como os protagonizados pela Vale na África e no Canadá, pela Petrobras na Bolívia, pela FoxConn na Ásia e assim por diante. Além disso, o perfil dos trabalhadores tem, paulatinamente, incorporado novos atributos, como a luta pela melhoria da qualidade de vida e das condições de trabalho, o que acarreta novas demandas para as organizações.

Acrescem-se a este panorama desfavorável alguns outros aspectos que merecem ser considerados: 0 aumento vertiginoso do processo de automação; a terceirização e o crescimento da economia informal; a redução do salário médio dos trabalhadores empregados em setores tradicionais; a exclusão de parcela majoritária dos com menor nível de instrução; e a presença expressiva da mulher no mercado de trabalho.

A alteração do perfil desse mercado pode ser observada também por outras características que gradativamente moldam novas formas de fazer negócios, novas circunstâncias para os relacionamentos entre líderes e subordinados ou mesmo entre as organizações e o seu entorno, com a consolidação da chamada economia colaborativa ou wikieconomia, baseada no processo de inovação aberta ou colaboração em massa.

\section{A REVOLUÇÃO DA WIKIECONOMIA}

Don Tapscott e Anthony D. Willians (2007, p. 21) já enfatizavam há alguns anos a mudança significativa ocorrida no mundo dos negócios com a ascensão do fenômeno da colaboração em massa, um processo que se acentua e se expande mundo afora:

0 acesso crescente à tecnologia da informação coloca nas pontas dos dedos de todos as ferramentas necessárias para colaborar, criar valor e competir. Isso libera as pessoas para participarem da inovação e da criação de riqueza em cada setor da economia. Milhões de pessoas já unem forças em colaborações auto-organizadas que produzem novos bens e serviços dinâmicos que rivalizam com os das maiores e mais bem-financiadas empresas do mundo.

Eles se referiam a um "novo modelo de inovação e criação de valor", chamado de peer production ou peering, que se constrói pelo fato de pessoas ou grupos se mobilizarem para propor novos produtos e processos, resolver problemas em equipe, instaurando uma gama formidável de bens e serviços, gratuitos ou não. 0 peering consolida alternativas revolucionárias como o "código aberto" e o compartilhamento muitas vezes sem limites que ameaçam os impérios fundados na propriedade intelectual.

As redes e mídias sociais geram um ambiente propício a essa nova postura e aprofundam a expansão desse modelo, que define plataformas digitais para participação intensiva, criando uma mentalidade wiki que revoluciona a relação das organizações com os seus stakeholders internos e externos. 


\section{ANO 10 • NÚMERO $19 \cdot$ 2os sem 2013 • ORGANICOM \\ COMUNICAÇÃO INTERNA E LIDERANÇA ABERTA:

É forçoso reconhecer que a maioria das empresas ainda não se sente confortável para abrigar esse novo modelo, particularmente no ambiente interno, porque elas continuam praticando uma gestão centralizada, que exige sistematicamente o "carimbo do líder-alfa", como explica Carlos Nepumoceno (2013). Na prática, a adoção do processo de inovação aberta - que coroa esse movimento pela wikieconomia, só tem efetivamente se consolidado em culturas corporativas que não se sentem ameaçadas pela abertura de seus processos para os parceiros externos e que acreditam nas vantagens da transparência do conhecimento.

Este artigo, respaldado em literatura recente das áreas de comunicação e administração, em pesquisas e levantamentos realizados por importantes institutos de pesquisa e consultorias do Brasil e do exterior, bem como emanálises e declarações de especialistas em recursos humanos e comunicação organizacional, demonstra a necessidade de mudanças paradigmáticas no processo de gestão e de relacionamento das organizações com os seus públicos internos. Especialmente, conceitua e alinha as vantagens do sistema de liderança aberta e da comunicação dialógica para dar conta dos desafios encontrados pelas organizações modernas para engajar, comprometer e reter os seus principais talentos, com atenção particular às gerações jovens que já representam parcela significativa do quadro atual de funcionários.

\section{AS DEMANDAS DA GERAÇÃO Y NAS EMPRESAS}

Segundo o Dieese (2011, p. 13), baseado nos resultados disponíveis da Relação Anual de Informações Sociais (Rais) para 2010, a rotatividade dos trabalhadores no mercado brasileiro chegou a $53,8 \%$, ou seja, mais de $50 \%$ da força total de trabalho no Brasil desligou-se do emprego, sendo substituída por porcentagem equivalente de trabalhadores admitidos.

Dados do IBGE evidenciam também que os trabalhadores estão ficando no emprego por um tempo cada vez menor. Em abril de $2012,16,7 \%$ deles estavam no máximo havia um ano no atual emprego e apenas 36,4\% dos empregados formais estavam no mesmo local de trabalho por mais de cinco anos (Giffoni, 2012).

Isso significa que as empresas não estão conseguindo reter os seus funcionários por uma série de motivos, de que têm resultado gastos excessivos não apenas para capacitar novos trabalhadores, mas também para cobrir os custos dos desligamentos. Estima-se que, especialmente os mais talentosos, em setores com demanda aquecida, têm procurado alternativas de trabalho mais recompensadoras ou, em muitos casos, se tornado empreendedores, buscando gerir 0 próprio negócio.

Especialistas em gestão de pessoas acreditam também que esse movimento constante da massa trabalhadora tem a ver com o perfil das novas gerações e da postura das chefias que não conseguem motivá-los. Essa situação já havia sido percebida por determinados autores, ainda que se reportando a uma realidade diferente da brasileira.

Arthur Jue, Jackie Marr e Mary Kassotakis (2010, p. 31) entendem que,

claramente, essa geração não será como as outras no que se refere a propósitos, motivação, perspectivas e expectativas. Eles valorizam o aprendizado contínuo, a confiança e a flexibilidade. É mais provável que os millenials vejam o mundo como um ecossistema interdependente e interconectado. 
Nicole Lipkin e April Perrymore(2010), psicólogas norte-americanas, que prestam consultoria a empresas dos Estados Unidos, exatamente com o objetivo de entender e integrar os jovens que pertencem a essa geração, garantem que é necessário ter uma visão abrangente de seu processo de educação, de sua relação com as tecnologias, seu perfil psicológico e sua disposição e suas habilidades de comunicação.

Lembram que eles são fruto de uma educação familiar que tem contribuído para inflar a sua autoestima, que os protege excessivamente e que se mostra benevolente com os seus atos e posturas nem sempre adequados. Elas admitem que a geração Y é fruto do que chamam de "pais-helicópteros", uma metáfora utilizada para designar "pais que 'sobrevoam' seus filhos, agindo sempre pelo bem deles, com o intuito de protegê-los, mas que acabam bloqueando sua capacidade de aprender com eles" (Lipkin; Perrymore, 2010, p. 42). Gestores por elas entrevistados alegam que os jovens se magoam mesmo com críticas construtivas, não respeitam facilmente a hierarquia e que falam o que pensam para qualquer pessoa, sem levar em conta o momento certo, o que, quase sempre, provoca embates com chefias que superestimam a disciplina e o respeito à autoridade.

Os jovens da geração Y não separam a vida pessoal da profissional, exigem flexibilidade em todos os sentidos (inclusive com respeito aos horários e prazos a serem seguidos), têm um conceito muito particular de lealdade - mais aos chefes (de que gostam, é claro) e aos amigos de trabalho do que propriamente às empresas que os empregam. Na prática, só respeitam quem os respeita e exigem sempre justificativa para as ordens que recebem, relutando em executar algo no qual não acreditam ou com que não concordam. Para mantê-los motivados no trabalho, é preciso efetivamente conquistá-los e eles estão abertos para isso porque, fundamentalmente, gostam de fazer amizades.

É indispensável, segundo essas autoras, atentar para o chamado ethos comunicacional desses jovens que exibem um perfil bastante singular. Eles estão sistemática e intensamente conectados e não têm qualquer receio dos avanços tecnológicos porque, como nativos digitais, não temem encontrar, pelo sistema de tentativa e erro, os caminhos e os benefícios das engenhocas tecnológicas. Têm disposição para o trabalho multitarefa (que para eles se confunde com entretenimento): veem televisão, interagem nas redes e falam pelo celular ao mesmo tempo. Ainda que isso possa representar, em princípio, uma perda de foco, também favorece a agilidade de resposta e a capacidade de expressão em vários meios ou linguagens, uma aprendizagem que a geração Y realiza por conta própria, com absoluta dedicação.

Essa adesão completa às novidades tecnológicas representa uma vantagem que as empresas precisam aproveitar, uma vez que a participação em múltiplas redes sociais se constitui em "um bem valioso, porque propicia o acesso a informações a partir de uma visão global" (Lipkin; Perrymore, 2010, p. 106) e, com naturalidade, eles se relacionam, ainda que virtualmente, com diferentes localidades, idades e setores. Eles aceitam, mais facilmente do que outras gerações, a diversidade, porque têm, em seu frenético processo de socialização eletrônica, amigos com diversos estilos de vida, crenças e posições.

Por terem amigos em todos os lugares, com distintos vínculos e compromissos, costumam identificar-se com as suas causas (ambientais, de respeito aos direitos humanos, contra o abuso de autoridade) e mobilizam-se com muita facilidade, endossando entusiasticamente movimentos, seja para a promoção de mudanças no bairro em que moram, seja para salvar o Planeta.

Todos esses atributos - entusiasmo, interatividade, estabelecimento de compromissos por motivos não necessariamente financeiros, capacitação tecnológica, rede de relacionamentos - podem ser apropriados pelas organizações e pela proposta 


\section{ANO 10 • NÚMERO $19 \cdot$ 2os sem 2013 • ORGANICOM \\ COMUNICAÇÃO INTERNA E LIDERANÇA ABERTA: OS DESAFIOS DE INCORPORAR A GERAÇÃO Y E AS MÍDIAS SOCIAIS}

de gestão e de comunicação interna para conquistar a geração Y no mercado de trabalho, mas é fundamental que os gestores se deem conta de que essas características positivas acarretam também uma contrapartida.

Em função de sua disposição para o exibicionismo tecnológico e de sua incrível capacidade de responder de forma instantânea às demandas ou provocações, eles não apenas reagem rapidamente às colocações das chefias (positiva ou negativamente), como ansiosamente as postam nas redes e as comentam, quase sempre incorporando a sua própria opinião. Costumam repercutir o que acontece dentro da empresa, vazando informações que podem ser ou estratégicas (aquelas deveriam ficar restritas ao ambiente interno), ou inconvenientes (as que tumultuam o clima organizacional - expressão da sua insatisfação no trabalho, críticas às chefias, aos colegas de trabalho e à própria empresa etc.).

Os gestores têm encontrado dificuldade para regular o processo de circulação das informações porque o acesso fácil e competente dos jovens às redes sociais, disponíveis a partir dos seus notebooks particulares, celulares ou tablets, os coloca, imediatamente e durante o tempo todo, em contato com o mundo.

A alternativa de impedir o acesso dos jovens às redes sociais (Twitter, Facebook e YouTube, por exemplo), nos casos em que a restrição se estabeleceu, tem se mostrado inócua e servido de motivo para sua insatisfação, visto que eles têm dificuldade para permanecer longe delas. Além disso, cerca de um terço dos chefes, segundo pesquisas recentes, já pertence à geração $Y$ e não concorda com essas proibições, mesmo porque não associa as redes sociais a problemas ou riscos, mas, sim, a oportunidades.

\section{COMUNICAÇÃO INTERNA E LIDERANÇA ABERTA}

Para incorporar essas duas novas realidades ao mundo do trabalho - a participação expressiva dos jovens e a convivência harmoniosa com as redes e mídias sociais -, as organizações precisam redimensionar a sua cultura organizacional, o seu processo de gestão e, particularmente, dispor de lideranças (não apenas de chefias) que tenham um perfil distinto dos atuais gestores, comprometidos com o ethos do tradicional líder-alfa.

Esse novo modelo de liderança afina-se com os novos tempos, mas é fundamental perceber que mesmo empresas tidas como modernas ainda exibem práticas administrativas derivadas de um processo de gestão autoritário, centralizador, nãoparticipativo e que afronta os princípios da emergente economia colaborativa.

O impasse do modelo atual se resume à necessidade anacrônica e imperativa, em quase todos os processos e procedimentos, do 'carimbo' do líder-alfa para que possamos seguir adiante... Há, portanto, um problema claro de eficiência entre o tempo que um líder-alfa atual leva para decidir e despachar diante da demanda variada, complexa e no tempo que a sociedade espera e necessita (e começa timidamente exigir), pois o consumidor/cidadão empoderado por novas ferramentas cognitivas reintermediadoras não é mais o mesmo. Está mais maduro. Além disso, já há um conjunto natural de empreendedores e investidores de capital de risco que já acordaram para a macro-oportunidade que têm pela frente (Nepomuceno, 2013, p. 34).

Carlos Nepomuceno defende a gestão dos formigueiros digitais, caracterizada pelo que ele chama de "comunicação química", ou seja, a capacidade que cada elemento da comunidade tem de ser seguida e seguidora ao mesmo tempo. Ele explica:

A comunicação química possibilita um rodízio meritocrático, pois cada formiga tem condições de ser um líder-alfa hiperprovisório, desde que tenha algo relevante a informar às demais, tal como: 'achei comida', 'não tem nada nesse caminho' ou ' há uma formiga esmagada adiante' (Nepomuceno, 2010, p. 38). 
0 autor conclui, de forma contundente:

Nossas organizações estão, por causa do controle informacional exercido ao longo das últimas décadas, voltadas para dentro, intoxicadas de si mesmas, sem princípios, egoístas, imediatistas, emocionais em um mundo que reivindica justamente o contrário (Nepomuceno, 2010, p. xviii).

Os especialistas em administração, particularmente em gestão de pessoas, e comunicadores comprometidos com a proposta de liderança aberta entendem ser fundamental superar a perspectiva funcionalista que vê a organização como uma entidade única para imaginá-la como um sistema aberto que se relaciona estreita e intensamente com o ambiente.

Nessa perspectiva, considerada fora do tempo, a comunicação é vista apenas como um instrumento, uma ferramenta para que objetivos organizacionais sejam alcançados, a partir de um processo de manipulação comandado pelos principais gestores.

É preciso, segundo Marlene Marchiori (2008, p. 187), considerar a perspectiva interpretativa, que possibilita "conceber as organizações como sistemas de construção social de significados compartilhados" e também a perspectiva crítica que prega "a existência de uma comunicação organizacional livre e aberta na qual a sociedade, indivíduos alcancem objetivos coletivos. Com isso, explica a autora, "a comunicação organizacional passa a ser mais ampla, não se restringindo a uma visão específica da organização e, sim, vindo tanto a organização como a sociedade a sofrer influências múltiplas" (Marchiori, 2008, p. 191-192).

0 problema de pensar a organização, a cultura e a comunicação de forma simplista, sem atentar para a diversidade de públicos, de percepções e de visões de mundo, cria armadilhas e equívocos na gestão da comunicação, sobretudo em uma época que se caracteriza por mudanças bruscas e dramáticas e pela vertiginosa aceleração dos contatos e da expressão livre e ampliada de opiniões. A organização que adota esta perspectiva imagina poder criar um consenso artificial, se acomoda, buscando, como é natural, permanecer em uma zona de conforto e, com isso, não se capacita para enfrentar divergências internas e externas.

Marchiori (2008, p. 178) defende a cultura como produto da comunicação ou, mais precisamente, que comunicação é cultura. "Sem comunicação, não há cultura, não há realidade social significativa".

Acreditamos que énecessário pensar a relação entre comunicação e cultura a partir de dois movimentos básicos: a comunicação forma a cultura - e, evidentemente, Marchiori está absolutamente correta quando defende essa tese; mas é possível entender também que organizações com um passado e uma trajetória têm uma cultura estabelecida (normas, princípios, valores, códigos de conduta, preferências e idiossincrasias), que acaba influenciando as suas práticas de comunicação.

Mesmo empresas que atuam no mesmo setor e que, portanto, buscam atender o mesmo perfil de clientes, e que contratam profissionais com um mesmo perfil para desenvolver atividades análogas, têm ethos comunicacionais distintos. Um exemplo clássico são as principais empresas áreas brasileiras - TAM, Gol e Azul - que apresentam "culturas de comunicação" distintas no que diz respeito à interação com seus públicos internos e externos, exatamente porque elas têm trajetórias, sistemas de liderança, origem e objetivos necessariamente não coincidentes. 


\section{ANO 10 • NÚMERO $19 \cdot$ 2os sem 2013 • ORGANICOM \\ COMUNICAÇÃO INTERNA E LIDERANÇA ABERTA: OS DESAFIOS DE INCORPORAR A GERAÇÃO Y E AS MÍDIAS SOCIAIS}

As mídias sociais e o perfil particular dos jovens estão revolucionando o mercado de trabalho e demandam uma nova proposta de comunicação interna, de liderança, de relacionamento entre os funcionários em uma organização.

A comunicação interna, no século XXI, assumiu uma nova dimensão e, na verdade, transcendeu os limites estabelecidos pelos locais de trabalho e pela proximidade física entre os funcionários. Pelo contrário, em boa parte das empresas, ela se efetiva mais em ambientes virtuais (intranet, portais, blogs, sistemas wiki de compartilhamento de informações, grupos de discussão, rede de e-mails etc.) do que a partir de contatos diretos que definem a chamada comunicação interpessoal.

Nesse sentido, a comunicação interna é hoje essencialmente pública, o que incomoda os gestores tradicionais pelo fato de ela estar, quase sempre, fora do seu controle, como sempre foi o sistema clássico de relacionamento com os públicos internos, que se reduzia a reuniões programadas, às notícias dos house-organs, às caixas de sugestões e ao até há pouco tempo inovador "café com o presidente".

Os jovens têm sinalizado para a importância de duas posturas novas a serem observadas na administração moderna: a flexibilidade organizacional e a descentralização do poder, porque elas se coadunam com a economia do conhecimento, baseada na inovação e na gestão participativa, e criam condições para o efetivo comprometimento dos públicos internos.

A liderança aberta pode protagonizar novas formas de relacionamento, mas, segundo Charlene Li (2011, p. 27-8), deve incorporar novas regras, como "respeitar o fato de que seus clientes e funcionários têm poder", "compartilhar sempre para construir confiança", "alimentar a curiosidade e a humildade", "manter a abertura responsável" e "perdoar os fracassos".

É fácil perceber que o atual modelo de gestão contraria essas regras, porque pressupõe que o poder deva ser centralizado, que o controle é imprescindível para manter a estabilidade organizacional e a governabilidade; estabelece limites para o compartilhamento, apoiado na tese de que todas as informações que circulam internamente devam permanecer ali enclausuradas; empenha-se firmemente para impedir mudanças, ideias novas; e, especialmente, é resistente (em alguns casos chega a ser truculenta) em relação à divergência de ideias e opiniões, notadamente quando elas questionam as expressas pelas chefias.

0 gap tecnológico existente entre os jovens que chegam às organizações - e que constituem parcela importante da força de trabalho (ou a maioria dela em determinados setores, especialmente aqueles associados à tecnologia da informação, comunicação etc.) - e os gestores tradicionais, muitas vezes avessos ou pouco capacitados para o uso das novas tecnologias, contribui para acirrar conflitos organizacionais.

Esse novo contingente de trabalhadores exige também melhores condições de trabalho, e isso significa oportunidades reais de desenvolvimento pessoal e profissional, relações saudáveis com os seus chefes, abertura para realizar projetos de seu interesse e para participar ativamente do processo de tomada de decisões. Além disso, como precisam de motivação externa (reconhecimento dos seus amigos, do mercado etc.), preferem trabalhar em organizações que são bem avaliadas, porque isso ajuda a inflar a sua autoestima.

O comprometimento dos funcionários exige, entre outros fatores, motivação permanente que só é obtida quando a liderança consegue estabelecer o alinhamento entre os objetivos da organização e as demandas da força de trabalho. Essa exigência é especialmente mais acentuada nos trabalhadores que se inserem na chamada economia do conhecimento, dentre os quais se destacam os jovens que integram a geração $Y$. 


\section{ANO 10 • NÚMERO $19 \cdot$ 2os sem 2013 • ORGANICOM \\ COMUNICAÇÃO INTERNA E LIDERANÇA ABERTA: OS DESAFIOS DE INCORPORAR A GERAÇÃO Y E AS MÍDIAS SOCIAIS}

A liderança aberta deve especialmente reconhecer que há novas formas de interação e que elas alimentam o fluxo de relacionamentos interna e externamente às organizações. Não é mais possível, como nos sistemas de gestão tradicionais, sufocar a expressão de ideias e opiniões, obstaculizar o compartilhamento de informações, impedir que os funcionários troquem experiências e percepções sobre o local de trabalho e mesmo sobre a postura de chefias e colegas. Logo, é imperioso desenvolver processos ágeis e competentes de feedback, estabelecer diálogos produtivos e explicitar abertamente as "regras do jogo", viabilizando uma abertura responsável que respeite as individualidades mas não ponha em risco a saúde do ambiente organizacional.

As chefias têm percebido que os jovens, mesmo antes de ingressarem no mercado de trabalho, têm opiniões sobre as organizações, porque podem avaliá-las diretamente nos seus portais institucionais e nas mídias sociais (algumas fan pages de empresas têm centenas de milhares de seguidores) ou ter informações sobre elas em rankings organizados pelo mercado (tipo "melhores empresas para trabalhar") ou junto à sua rede de relacionamentos etc.

As redes sociais possibilitam, na feliz expressão de Raquel Recuero (2009, p. 117), a "difusão epidêmica de informações", e esta disseminação tem relação com o incremento do capital social relacional - que promove a integração e o estreitamento dos laços sociais - e o capital social cognitivo - que tem a ver com o incremento do conhecimento.

As organizações têm estado cada vez mais atentas à necessidade de estabelecer redes sociais corporativas com o objetivo de cumprir adequadamente o seu processo de interação com os seus stakeholders, internos e externos.

Segundo a Deloitte, consultoria norte-americana com experiência e interesse direto no processo de difusão e gestão utilizando as redes sociais,

até o final de 2013, mais de 90\% das empresas da lista das 500 maiores da revista americana Fortune deverão adotar uma rede social corporativa - dois anos atrás eram $53 \%$. Em geral, o principal objetivo dessas redes corporativas é fazer com que os funcionários participem do processo de inovação da companhia - não deixando esse assunto restrito a uma área específica (Furlan, 2013, p. 107-8)

Charlene Li e Josh Bernoff (2009, p. 225-42) afirmam que os groundswells internos funcionam quando a gestão escuta, a participação das pessoas é estimulada, há o encorajamento dos rebeldes, fazendo com que a resistência diminua. Eles defendem a criação de uma mentalidade groundswell, entendendo que, na comunicação interna, é preciso substituir o individualismo das redes e mídias sociais tradicionais, pautado pela expressão de interesses pessoais, alinhando-o com os interesses da companhia. A melhor alternativa, para esses autores, é criar comunidades virtuais, formadas por pessoas que, ao mesmo tempo, se conhecem, partilham a noção de pertencimento a uma empresa e que estão vinculadas a objetivos, valores e cultura comuns.

As ferramentas de mídia social apresentam novos modos para um maior engajamento dentro de uma ampla área de negócios como nunca visto antes. Um webcast possibilita que todos os empregados escutem a mesma mensagem. Os blogs criam um diálogo visível e convidam ao pensamento, análise e respostas independentemente das ideias de um líder e de um outro funcionário. Qualquer pessoa pode contribuir naquilo que ama ou que é sua área de especialidade através de wikis e fóruns de discussão. Líderes de uma organização podem resolver problemas complexos com maior eficiência, se simplesmente pedirem a opinião e escutarem as respostas de suas equipes (Jue; Marr; Kassotakis; 2010, p. 96).

A liderança aberta, portanto, não deve estar voltada apenas para os clientes, como forma de incorporar sugestões para 0 lançamento de novos produtos e processos ou para o refinamento dos já existentes, mas capitalizar o conhecimento dos 


\section{ANO 10 • NÚMERO $19 \cdot$ 2os sem 2013 • ORGANICOM \\ COMUNICAÇÃO INTERNA E LIDERANÇA ABERTA:

públicos internos, envolvê-los direta e intensivamente no processo de produção e de gestão de modo a promover um efetivo engajamento.

A comunicação interna desempenha um papel fundamental no sentido de promover a articulação dos funcionários, consolidando relacionamentos duradouros, confiáveis e produtivos, bem como para comprometer os públicos internos com a solução coletiva de questões de natureza institucional.

Diferentemente do modelo de gestão que vive refém do líder-alfa, a liderança aberta não se limita a uma ou poucas chefias, mas possibilita, num processo dinâmico de capacitação e aprendizado permanentes, a formação de múltiplos líderes abertos, que atuam como catalisadores, com objetivos e visão compartilhados. Na liderança aberta, os líderes não se definem pela posição que ocupam no organograma da organização.

Isso significa que existem oportunidades para que trabalhadores individuais pratiquem as competências de liderança aberta e experimentem o poder, o trabalho em colaboração e a influência mais cedo em suas carreiras. Quanto mais relacionamentos positivos você tiver, mais poder alcançará

A liderança aberta, em resumo, não é algo para ser praticado apenas pelo alto escalão da empresa. Pelo contrário, é uma atitude que precisa ocorrer em todos os níveis da organização, com líderes de equipe e funcionários praticando-a em diferentes níveis e de uma maneira diferente dos executivos (Li, 2011, p. 237).

Novamente, a comunicação interna é vital para que essa "cultura de apoio à abertura" se estabeleça e é fácil perceber que essa cultura não será plasmada pelas práticas tradicionais de comunicação, tão mal avaliadas na atualidade, como as intranets que não passam de murais estáticos de avisos e com reduzida participação, os house-organs que se limitam a promover chefias, com seu tom propagandístico e laudatório às organizações, ou com propostas limitadas de participação, como a "caixa de sugestões" e as "conversas com o presidente".

Aqueles que imaginam que esse novo modelo de gestão e, portanto de comunicação, está longe de acontecer não devem estar acompanhando o movimento realizado por inúmeras organizações pioneiras em todo o mundo, como a Unilever, a $P \& G$ e a Natura, de forma exemplar, no Brasil. Elas já se deram conta de que é estratégico buscar efetivamente 0 compartilhamento de informações e conhecimentos, a distribuição do controle e até correr riscos porque essa é a característica da economia do conhecimento.

\section{CONSIDERAÇÕES FINAIS}

O olhar atento de pesquisadores, estudiosos e profissionais de comunicação e administração, especialmente os dedicados à análise do relacionamento das organizações com os públicos internos, evidencia a urgência de mudanças importantes nos processos de comunicação interna que ainda vigoram na maioria das empresas brasileiras.

De maneira geral, fica evidente a necessidade de um novo modelo de gestão, especialmente no que respeita à relação entre as organizações e seus públicos internos e, mais especificamente ainda, à interação entre chefias e subordinados, com atenção particular aos funcionários que integram a chamada Geração Y. 
A implementação de um sistema de liderança aberta, a disposição para praticar uma comunicação dialógica e 0 reconhecimento da importância de se contemplar os funcionários como protagonistas são atributos fundamentais dessa nova cultura organizacional. Ela deve ser plasmada para enfrentar os desafios decorrentes da emergência das mídias sociais, da elevada rotatividade do quadro funcional e, sobretudo, da evasão de talentos jovens.

A proposta de um novo modelo de gestão repercute, de maneira indiscutível, na construção de um novo ethos comunicacional fundado no uso intensivo, mas responsável, das mídias sociais no ambiente interno, na valorização da participação dos funcionários e na adoção de sistemas e canais de relacionamento que promovam a interação e favoreçam o fortalecimento do fluxo de comunicação/informação ascendente.

Além disso, será necessário rever os instrumentos e espaços tradicionalmente utilizados para a interação entre organização e chefias com a comunicação interna (house-organs, intranets, reuniões formais etc.), com o objetivo de oxigenar 0 relacionamento e contribuir para que os funcionários se comprometam efetivamente com os objetivos estratégicos das organizações. 0 aumento da produtividade e o engajamento estão definitivamente associados à melhoria da autoestima dos funcionários e à percepção de que as organizações nas quais trabalham estão realmente comprometidas com o seu desenvolvimento pessoal e profissional.

\section{REFERÊNCIAS}

DIEESE. Rotatividade e flexibilidade no mercado de trabalho. São Paulo: Dieese, 2011.

FURLAN, Flávia. Sem medo das redes sociais. Exame CEO, São Paulo, Editora Abril, p. 104-109, 2013.

GIFFONI, Carlos. Trabalhador muda mais de emprego. Valor Econômico, São Paulo, 08/06/2012. Disponível em <http://www. fazenda.gov.br/resenhaeletronica/MostraMateria.asp?page=\&cod=815666>.

JUE, Arthur L.; MARR, Jackie Alcade; KASSOTAKIS, Mary Ellen. Mídias sociais nas empresas: colaboração, inovação, competitividade e resultados. São Paulo: Évora, 2010.

LI, Charlene. Liderança aberta: como as mídias sociais transformam o modo de liderarmos. São Paulo: Évora, 2011.

LI, Charlene; BERNOFF, Josh. O fenômeno social nos negócios. Rio de Janeiro: Campus, 2009.

LIPKIN, Nicole; PERRYMORE, April. A geração Y no trabalho. Rio de Janeiro: Elsevier, 2010.

MARCHIORI, Marlene. Comunicação organizacional e perspectivas metateóricas: interfaces e possibilidades de diálogo no contexto das organizações. In: OLIVEIRA, Ivone de Lourdes; SOARES, Ana Thereza Nogueira (Org). Interfaces e tendências da comunicação no contexto das organizações. São Caetano do Sul, SP: Difusão Editora, 2008. p. 179-200.

NEPOMUCENO, Carlos. Gestão 3.0: a crise das organizações. Rio de Janeiro: Campus, 2013. 
RECUERO, Raquel da Cunha. Redes sociais na internet. Porto Alegre: Sulina, 2009.

TAPSCOTT, Don; WILLIANS, Anthony. Wikinomics: como a colaboração em massa pode mudar o seu negócio. Rio de Janeiro: Nova Fronteira, 2007.

Artigo recebido em 23.09.2013 e aprovado em 24.11.2013. 